\author{
Pienaar, HE ${ }^{1}$ \\ University of Pretoria
}

\title{
Overture to practical theological facilitation
}

\begin{abstract}
The author introduces what he calls practical theological facilitation. The metaphor and activity of facilitation is regarded as an important lens and dimension in, and to, practical theology. It is espoused not only as an approach to standing practice but in particular as a professional-vocational activity or role in itself. This role is called practical theological facilitation or is referred to as a facilitative approach in practical theology.

Practical theological facilitation consists of two aspects, namely, professionalvocational facilitation and facilitative consulting. These two aspects relate in some ways to what the reader might understand from what practitioner facilitation and conventional consulting involve. There are however notable differences. For these differences and distinguishing accents to facilitation and consulting, the tradition of inquiry, particular accents in practical theology, and the subdiscipline of pastoral therapy are judged to be important conversational partners.
\end{abstract}

\section{INITIAL BRUSH STROKES}

With this article I introduce the idea of practical theological facilitation. As with all things, how I came about this theme has a story. While the story is connected to many motivations in favour of practical theological facilitation neither the story nor the motivations will be addressed here. I will attempt rather, as with the way many musicians commence, to write initial rhythmic phrases, melodies and harmonies towards a larger composition. Although I have developed supporting arguments in other works relating to neutrality and epistemology in facilitation this article marks the first and introductory work on the matter. It can only be but a prelude or overture to something more, as part of the larger composition of practical theology.

Practical theological facilitation is founded in an interdisciplinary dialogue. Apart from my ordinary world, which is practical theology, a discipline in the larger domain of theology, I draw on two conversational partners. These are practitioner facilitation and conventional consulting. ${ }^{2}$ The aforementioned fields of practice might, to some, conjure workplace association that are most always informed by psychology and/or economic and management sciences. Along these lines professional fields might spring to mind such as organisational and industrial psychology, organisational development, or any other formal training that may have taken a consulting.

What one can appreciate regarding practical theological facilitation is that its focus lies with the medium as it takes shape in any given discipline or field of professional practice mentioned above. Roger Schwarz (2005:25) is of the opinion that facilitation speaks to principles of effective human interaction. There is no doubt in my mind that, while it is relevant to workplace settings,

1 Dr Elmo Pienaar is currently a Research Fellow of the Department Practical Theology, University of Pretoria who is working under supervision of Prof Julian Müller from the same department.

2 Throughout the article I kept with the custom in literature. The verb form is mostly used in reference to the practice of consultation (i.e., consulting) and the noun in reference to facilitation. See in this regard many of the titles of works referenced. 
it is not restricted to any particular field of practice since it relates to human interaction in various contexts. It is informed by (is in conversation with), and informs (relates to) a multitude of practices in, for example, humanities, economic sciences, and social sciences.

\section{CONCEPTUAL CLARIFICATION}

The idea of facilitation as it relates to practical theology specifically should be thought of as having traffic in opposite directions.

One lane involves facilitation as a key metaphor that heads into the discipline of practical theology. As such it has relevance to any of the many practical theological subdisciplines, for example, homiletics, liturgical studies, pastoral counselling, and congregational studies. This represents a facilitative approach 'to' practical theology or facilitative practical theology. Viewed in this way, facilitation provides an accent relevant to the subdisciplines that I will not elaborate on in this article.

The other lane involves facilitation as (what could be) a professional role that heads from practical theology to society in view of all its organisations, institutions and cultures; towards the practice of life even outside of the immediate concern with congregational or even ecclesial contexts. This represents a facilitative approach 'in' practical theology, or then that which we will call practical theological facilitation.

The article has two broad sections. In section A, I refer to accepted general practical theology approaches but also specific accents that I deem relevant to a facilitative approach in, and to, practical theology. Section B puts forward initial notes on the musical staff of practical theological facilitation (as opposed to facilitative practical theology) as it finds expression in professionalvocational facilitation and facilitative consulting.

\section{SECTION A: APPROACHES AND ACCENTS IN PRACTICAL THEOLOGY}

Practical theology ${ }^{3}$ in my estimation has for the most part been a type of chameleon discipline. The story of its development attests to having fought hard battles for its integrity and place as a discipline. ${ }^{4}$ I will not go into that here but the reader should know this: It is due to this fiery furnace development that I think it is superbly positioned for interdisciplinary pursuit and academically extremely well positioned to fulfil the facilitative endeavour I envision.

Three intra-disciplinary matters aid the conversation regarding a facilitative approach in, and to, practical theological: (1) the way in which the discipline has been able to tie together different approaches or rationalities in one design, (2) two conceptual developments from about the 1970's that have become part of the foremost musical clefs in which the genre of practical theology is composed, and (3) certain epistemological accents (or to follow our metaphor), rhythmic ideas, melodies and harmonies, perhaps even a different time-signature as part of the larger composition of the music of practical theology.

\subsection{Different approaches in one design}

In the courtship between facilitation and practical theology, from practical theology's side

3 This section does not aim to be comprehensive in the way that it reflects the rich tapestry of practical theological tradition and inquiry. For such a pursuit, as a place to start from, see Richard Osmer's recent article on what he sees as a current international perspective on practical theology, especially in conjunction with his book on an introduction to the field of practical theology (respectively published in 2011 and 2008).

4 For some of these challenges see Don Browning, 1991:4. 
it brings a rich tradition of inquiry in what Osmer (2008:2) refers to as paradigms that are constituted on a metatheoretical level. De Roest (1998:25) mentions that Bäumler had already in 1976 expressed that practical theology is not characterised by a single method; advocating that different methods should be used in a practical theological ensemble. Dingemans (1996:91) notes that coalescence of approaches and complementarity of methods are key phrases in practical theology.

Consequently attempts were made to establish a harmony between major approaches (De Roest 1998:22) and in this regard De Roest mentions Van der Ven, Mette, and Browning. Browning (1991) for instance puts forward a process of descriptive, historical, systematic, and fully practical theology in his work on a Fundamental Practical Theology. Heitink (1993:174) delineates three approaches in practical theology. To him the practice, or what he calls action theories (Heitink 1993:174), of practical theology is placed in an interconnected play between a hermeneutical cycle (with the purpose of understanding), an empirical cycle (with the focus on explaining) and a strategic or regulative cycle (with the intention of changing) (Heitink 1993:161). De Roest (1998:22-25), following Van der Ven (1993), distinguishes between an 'empirical-analytical', a 'hermeneutical' or a 'critical-political' approach or accent. Osmer and Schweitzer (2003:1) refer to practical theology's four distinguishable but mutually influential tasks being descriptiveempirical, interpretive, normative and pragmatic with the relationship between them part of a hermeneutical circle (Osmer \& Schweitzer 2003:1-5; Osmer 2011:2). Osmer (2011:3) refers to these as the disciplines reflective equilibrium in that "virtually all practical theologians today, give at least some attention" to the above.

Attempts to build bridges between approaches, also outside of theological traditions, is still relevant today. Arbnor and Bjerke (2009:323-348), with their work Methodology for creating business knowledge, promote a trifold approach between three perspectives they distinguish in research, namely analytical-empirical, systemic and an actor's view. They refer to, and elaborate on what they call a methodology of complementarity. ${ }^{5}$

I would like to go one step further in making a connection between the notion of different models, cycles, accents or approaches to the idea that these represent different transversal rationalities. The notion of transversality pertains to Van Huyssteen (2000:429). This is important to us in that facilitation, more so even practical theological facilitation will have to work with various proponents of differing perspectives, through what philosophers speak about as "transversal performance of rationality" (Van Huyssteen 2000:429). Stated differently (Van Huyssteen 2000:429) the facilitator's task relates to the dynamic interaction of dialogue where dissimilar rationalities converge towards a vanishing point without assimilating the other. ${ }^{6}$ All approaches become part of the dialogue wherein interjudgemental reliability (Baart 2003:147) rather than traditional research values of reliability, validity and generaliseability takes prominence.

Not that they necessarily are, but any of the above mentioned approaches or models could still pass for, and be practiced from, a modernist thought paradigm that relies on the idea of a knowable objective reality. For instance, the systems view ${ }^{7}$ as a precursor to social

5 They do not use the word complementarity in an ordinary sense where two parts make up a whole (2009:341). They rather propose that when, for instance, techniques, thinking and ideas of one methodological approach is used in another, they are reshaped on the way; they change form and content with context (2009:342, italics in original).

6 In this Van Huyssteen (2000:429) relies on Donald Capps (1999) concerning the relationship between theology and psychology.

7 This is similar to second order cybernetics, or constructivism - as opposed to constructionism - or as referred to by Brown (2010:251) 'second order epistemology' - as opposed to 'third order epistemology' (2010:253). 
constructionism (Müller 1996:80; Freedman \& Combs 1996:1-8), although very interpretive, and emphasising understanding, and while not disinterested in explaining (as with the analytical view), still espouses the notion of an objective reality (Arbnor \& Bjerke 2009:50-51; Müller 1996:80-81). ${ }^{8}$ In addition to the family therapy context that Müller (1996) writes about, De Roest (1998:26) refers to Paul Dietterich (1998) as an example of systems thinking in relation to general ministry and mission.

Here over, practical theology also saw the development of post-modern (as in, after-modern) related approaches. Julian Müller is one such scholar who has developed, and worked with other scholars in developing such approaches. Along with these approaches came a shift in emphasis from ontology (the nature of reality) to epistemology (forming of reality) (Müller 1996:80). These approaches are expressed particularly in social constructionism, narrative practice and postfoundationalism ${ }^{9}$ which I deem important in furthering a facilitative approach in, and to, practical theology. They take serious the construction of realities based on social interaction and language, underscoring amongst other notions, narrative rationality, contextuality, interdisciplinarity, and intersubjectivity.

Arbnor and Bjerke (2009:51) provide us with the useful and creative distinction that differentiates the analytical-empirical and systemic views with what they call an actor's view. This view in turn relates to postmodern specific approaches in practical theology. Herein the person is always an actor that is part of the construction. Whereas the prior mentioned approaches (analytical and systemic) assume a fact filled or factive reality, the latter puts forward a factified reality.

\subsection{Two central clefs of recent practical theology}

A second practical theological layer that informs practical theological facilitation is sought in vital changes in the discipline over the past five decades. I think of these changes as stemming from the postmodern cradle of practical theology. It has to do with the discipline taking its focus in action (practice) (in piano, for instance, the left-hand clef) and doing so interpretively (in piano, for instance, the right-hand clef).

It was from the end of the sixties that through gradual agreement practical theologians' point of departure were situated in practice (De Roest 1998:19); hence, leading in an era of a movement between 'practice-theory-practice.' Browning (1991:9) remarks that this movement indicates the fundamental process of human thinking. The change was so encompassing that practical theology came to be known as a handlungswissenschaft, meaning a science of action whereby normative prescription or theological description paved way to social-scientific description (De Roest 1998:20). Social sciences were therefore an early interdisciplinary partner.

Of equal importance to situating practical theology's formal object of inquiry in practice (resulting from the social sciences especially), the 1970's endowed us with an interpretive framework. This was made possible in particular with the resurgence of the practical philosophies (Browning 1991:3). It is perhaps for this reason that family therapy (a discipline native to me) went through a "philosophical midlife crisis" (Nichols \& Schwartz 1991:143, in Müller 1996:80). Hereby modernist approaches had to pave way for the postmodern that underscores meaning, interpretation, and intersubjectivity of knowledge (Müller 1996:80). It signified a movement

8 It should be noted that a systems approach can be practiced from a postmodern constructivist position as Fourie (2010:380) drawing on Poerksen (2004) reminds us: Our views cannot claim ultimate truth seeing that it is a construction as any other.

9 See in this regard as cited in this article Müller 2011a, 2011b, 1996, and co-authored with Demasure 2006. See also other scholarly contributions from 2004, co-authored with Schoeman 2004, co-authored with Van Deventer and Human 2001. 
from the prominent systems discourse to families as interpretive communities (Müller 1996:80) or what Paré (1995:2) refers to as storying cultures.

\subsection{Epistemological accents in the larger composition}

With development of such remarkable calibre - with the prominence placed on a science of action and an interpretive lens - it was only a matter of time until overt postmodern accents or harmonies were to be composed and performed. These accents in question find expression in social construction, narrative-, and postfoundational practice as I have referred to above. I mention it here, again, since these accents do not necessarily constitute models. In my particular narrative, these concepts have come to be rooted in the subdiscipline of pastoral care and counselling.

With the informing accents of narrative practice, social constructionism and postfoundationalism, the focus lies strongly with the individual embedded in a context; less so on a general characteristic or agenda of practical theology as a discipline. To reiterate, the implication is that the practical theologian's life becomes an artwork in living on the ecotone ${ }^{10}$ between, for instance, church and academia (Müller 2011b:3-4), or adding as Tracy (1998) does, the public sphere or society. This implies firstly that there is enough scope for a practical theologian to involve him or herself in matters where one might not ordinarily encounter his or her participation. Secondly it means that such an approach opens up vistas for interdisciplinary conversation with humanities, at least in the same measure that practical theology has been in conversation with the social sciences for quite some time.

It is against the importance of postmodern harmonies that we find confluence between facilitation and certain epistemological accents in practical theology. One of the reasons for this is because facilitation carries with it a particular view of how we know, of epistemology. Although there is in my evaluation still much room for epistemological discussion in practitioner facilitation, in many respects facilitation employs and points in the direction of postfoundational epistemology.

\section{SECTION B: FACILITATION}

The previous section introduced the kind of things in practical theology that bears reference to my proposal. It related to (a) different approaches in one model, (b) a focus on action/ practice and interpretation, (c) in conjunction with the accents of narrative practice, social constructionism, and postfoundationalism. The following section serves to convey my particular ideas about facilitation.

\subsection{Disambiguating facilitation}

In my estimation, the word facilitation is generally employed in three ways: it is used colloquially, in many instances it is used to denote a skilful-postural approach, and lastly it could also have a professional-vocational connotation.

The frequent understanding is one that we encounter in everyday use. Let me call this $s$ a colloquial understanding and bear in mind that it does not relate to what this article is about. A physiotherapist will use a phrase such as the 'facilitation of movement.' Hereby he or she might help patients to enlarge their range of post-operative physical motion. Whether the context is a personal or vocational one, i.e. used in everyday language or a technical term the word is still used colloquially.

10 An 'in-between' patch of landscape where two ecologies are in tension. Accessed 4 March 2012, http:// en.wikipedia.org/wiki/Ecotone 
The second understanding denotes a specific approach to things. I will call this a skilfulpostural approach. Many professions could benefit from a skilful-postural approach to what they do. In so doing someone in their formal role as teacher, mediator, coach, manager, group therapist, leader, and may I add, practical theologian will seek to provide space for others to build relationships, think and reflect, exercise choice and express their creative potential (Hunter et al. 2007:32).

The line however becomes somewhat indistinct. Taking the practice of coaching as an example (business or life coaching for instance), many claim to have a facilitative approach. In coaching surveys conducted from 2003 to 2007, Palmer and Whybrow (2008:9, 10) differentiated roughly 28 approaches in coaching e.g. a cognitive-behavioural or neuro-linguistic programming (NLP) approach. The majority describe their practice however (irrespective of whether they are cognitive-behavioural, narrative based or other) as facilitative.

Confusion sometimes arises when people use the word facilitation in, especially, a helping professions context, purely colloquially such as it seems above. Adding to this confusion, facilitation has been a rather vague and poorly understood practice, mastered only by human resources types (Bens 2005:1). The understanding I propose is that a skilful-postural approach needs to be accompanied by a high degree of awareness and self-reflection regarding the role of facilitation as it relates to whatever activity or profession is in question.

Thirdly, the word facilitation is used in, what I refer to as, a professional-vocational manner. It relates to classical-, practitioner, or proper facilitation. Along these lines Hunter et al. (2007:32) refers to the facilitator as practitioner. The intention here is that of a formal role that is adopted, to which some kind of remuneration for services is often in question.

The contexts in which formal facilitation might be appropriate or wherein it could play a significant part vary considerably. It might involve things such as facilitation of strategy workshops, team conflict resolution, change processes or mergers and acquisitions.

The degree to which I propose the practical theologian could take up the facilitative role lies somewhere between a skilful-postural and a professional-vocational role, and could at times be one or the other. Facilitative practical theology could be said to require a skilful-postural stance whereas practical theological facilitation takes its expression in a professional-vocational role. Bear in mind that there is also a counterpart to the professional-vocational role of practical theological facilitation, namely, facilitative consulting.

While both aspects of practical theological facilitation could be professional and vocational, in this article I restrict the reference to professional-vocational facilitation to denote practitioner facilitation; pertaining to an in-the-moment, and mostly a direct contact event between facilitator and a group. Here over, although not entirely unrelated to the above description of Ingrid Bens regarding practitioner facilitation, facilitative consulting has to do with processes that develop over time and does not necessarily require direct conversational engagement with all relevant parties at every step of the way. In the reader's mind this might strongly relate to proper consulting rather than to facilitation.

Henceforth, under the idea of practical theological facilitation, I put forward my two notions of the aforementioned: professional-vocational facilitation and facilitative consulting. Both of these have the dimensions of process and communication as integral concepts. The understanding of process and communication in both professional-vocational facilitation and facilitative consulting are very much related. With facilitative consulting however its scope widens. Müller (2000:69) notes that he had done away with the distinction he made in his book dating back to 1996, Om tot verhaal te kom, between process and agenda. I would like to retain something of that notion as it is currently an important distinction in facilitation. Bens (2005:9) notes that the words process (how) and content (what) are words that the reader will hear over and over again. 


\subsection{Professional-vocational facilitation}

This role is one that readers might recognize from experience in workplace settings. It is less ambiguous than facilitative consulting.

Ingrid Bens (2005:5) offers a description of the task of the formal practitioner facilitator. She explains that a facilitator is one who "...contributes structure and process to interactions so groups are able to function effectively and make high-quality decisions. A helper and enabler whose goal is to support others as they pursue their objectives."

The above takes shape along the lines of an in-the-moment event where mostly one person, the practical theologian facilitator, engages a group in process and communication. In this role the facilitator is mostly able to speak directly and comfortably with all people in the group although large group formats are not necessarily out of view.

\subsubsection{Process}

The idea of process refers to everything that happens from initial contact with a client, therefore even before any form of official inquiry is made. The client may be community leaders, the government, a ministry team, or a manager. The process engagement stops officially when there is mutual understanding that no more involvement or further responsibility is required.

As an example of such a process Bens (2005:41-48) proposes seven stages in facilitation: (1) Assessment and Design; (2) Feedback and Refinement; (3) Final Preparation; (4) Starting-; (5) During-; (6) Ending a Facilitation; (7) Following Up on a Facilitation.

A pivotal concern regarding a broad understanding of process requires one to consider how to establish, what White and Nair refers to as, 'participatory communication' (1999:36-37) throughout. Hereby people "have a right to voice their views and become active partners in the development process" (White \& Nair 1999:36-37).

With professional-vocational facilitation, stages 4 to 6 are what most would see as actual facilitation: An in-the-moment event and direct contact with a group. In these stages, of actual facilitation, the notion of process becomes especially important. In these stages process consideration is concerned with the manner in which the facilitator will enable the process (unfolding of an engagement) to take place efficiently and effectively (Bens 2005:45). The particulars of 'how' is more adequately answered by the next section, by the type of conversation sought and the proficiency of the facilitator in that communication.

\subsubsection{Communication}

In order for the group to be efficient and effective as mentioned above the facilitator engages through any number of, what is regarded as, core practices in the profession (Bens 2005:35) for example to listen actively, help identify needs, bringing everyone into the discussion, accepting and using feedback, and asking relevant and probing questions.

What I would like to underscore from my specific tradition of inquiry is not so much what the relevant core practices are or might entail but the nature of the conversation. The nature of the conversation is characterized by three notions: Preference for (1) narrative logic and stories as foremost linguistic framework, as underpinned by social constructionist epistemology that constructs and moulds reality (Freedman \& Combs 1996:22). Arbnor and Bjerke (2009:49) call our attention to reconstructed-logic, which aligns with practical theology's choice for an interpretive framework and relates to the notion of narrative practice. (2) Yet another aspect is transparency: Facilitator, Miki Kashtan, helps us in this matter when she chooses for deliberate transparency in what she calls the art of transparent facilitation, over against the idea that the facilitator should be neutral (Kashtan 2005:573). An important aspect of being transparent consists of animating presuppositions, values and attitudes. (3) Another aspect involves "deep listening" in a "sacred 
space" (Hunter et al. 2007:98) as the basis on which conversational realities evolve.

\subsection{Facilitative consulting}

Being more ambiguous than professional-vocational facilitation, facilitative consulting warrants more explanation.

Since what I describe might sound to the informed reader like consulting I would like to clarify my choice for the accent rather on facilitation.

\subsubsection{Consulting or facilitation?}

Among the reasons for why I refrain from calling this outright consulting is that my intention with it resembles the values or beliefs that professional-vocational facilitation assumes, e.g. equal regard despite rank or position; that people are capable of doing the right thing; that the process can be trusted (Bens 2005:8). My choice is further underlined by my view that the latent and implied epistemology of facilitation differs to that of consulting: Facilitation relates to a postmodern epistemology that in my tradition requires a not-knowing stance: In pastoral narrative therapy, the pastor takes a 'not-knowing' posture wherein "the therapist does not challenge the client's version of reality with preconceived therapeutic knowing" (Demasure \& Müller 2006:416). Here over, conventional/classical consulting exudes an attitude of knowing, of transferring my knowledge to you, of modernism.

I have looked to facilitation literature and found that there are indeed expressions of facilitation that relate to consulting. These expressions are important as they are included in what is put forward as an international handbook of facilitation (which in other words it gives itself out as an important voice on the matter of facilitation); The IAF handbook of group facilitation. See in this book the chapter contribution from Troxel (2005:259-608) that relates to organisational processes that would normally be the endeavour of consulting. This facilitative consulting approach is also relevant outside of the corporate organisational context and could play a pivotal role in large scale community development processes, as seen in The Art of Facilitating Participation. Releasing the power of grassroots communication (ed. White 1999).

Although that might not be the intention of the said literature it still suggests that there is adequate motivation to develop a theory along these lines. There is merit, therefore, in grouping together professional-vocational facilitation and facilitative consulting under the umbrella term of facilitation. Indeed many facilitative informed practices (leadership, coaching, training, and so forth, as referred to by Schwarz 2005:25), with adaptation to some of its central concerns, fits within the framework of practical theological facilitation. The practice of coaching can for instance refer to a regulative (to borrow from Heitink above), or strategic moment (to borrow from Browning) in one facilitative consulting design. All of these moments are however informed by facilitation.

There could be any number of 'moments' (as for instance, coaching, as an element in professional-vocational facilitation) as long as it equates with, in a broad sense, practical theological concern, and purposefully aligns with the values and practice of facilitation. In similar fashion narrative therapy, for example, is not pastoral narrative therapy if it does not, as with pastoral therapy, in some way pertain to reflection on practice from the perspective of the experience of the presence of God (Demasure \& Müller 2006:416) while simultaneously doing so from a narrative epistemology.

Schwarz, in contributing to the handbook of the International Association of Facilitation, acknowledges the depth to which professional-vocational values and principles of facilitation have rooted in other practices: In this he refers to the facilitative consultant, facilitative coach, facilitative trainer, and facilitative leader saying that they all rely on underlying core values and 
principles of facilitation (2005:25). I still regard these as displaying a skilful-postural approach to something else. It is therefore somewhat problematic that Schwarz $(2005: 25)$ mentions facilitative consulting on the same line with the others. Then he proceeds, and herein I agree. More so than being based on principles of facilitation (e.g., facilitative leadership) it is said that these underlying core values and principles are principles of effective human interaction (2005a:25). This underscores my preference for stating that facilitation and not consultation is in this approach the primary concept. The measure in which I see facilitation as an epistemological statement tips the scale in view of facilitative consulting as something other than merely consulting that takes a skilful-postural facilitative slant.

\subsubsection{A basic understanding of facilitative consulting}

Facilitative consulting has a much larger agenda and is much more elaborate than professionalvocational facilitation. It is generally a community, institution, or organisation-wide undertaking and has the intention of effecting change on a much larger scale. It is more aptly viewed by requiring involvement in a process over time, i.e. not restricted to an in-the-moment event, with an organisation, institution or movement as a client, and does not necessarily involve direct conversational engagement of the practical theologian facilitator with all parties. Professionalvocational facilitation will inevitably form part of the larger endeavour.

It is especially with facilitative consulting that practical theology's tradition of different accents in one design aids us. The practical theologian will find him- or herself in a position of having to work with different modalities of inquiry and practice. Where practical theology aids as well is in how all of these come together communicatively and interpretively.

Again the process and communication dimensions of facilitation deserve discussion.

\subsubsection{Process}

I have given an indication earlier of what the process aspect of professional-vocational facilitation might involve. With regard to consulting proper, Cope (2010) designs his entire book around the process of consulting and calls it The Seven C's of Consulting. It consists of the following stages: (1) Client; (2) Clarify; (3) Create; (4) Change; (5) Confirm; (6) Continue; 7) Close. Peter Block (2000) puts forward Flawless Consulting and distinguishes five stages of consulting, namely (1) Entry and Contracting; (2) Discovery and Dialogue; (3) Feedback and Decision to Act; (4) Engagement and Implementation; (5) Extension, Recycle, or Termination.

To be sure, there are numerous processes (models, approaches and the like). Consequently, while the process dimension of the facilitative consulting role is concerned with establishing the why, who, what, and when, practical theological facilitation lingers especially with 'how' as informed by epistemology. With facilitative consulting the processes role may also involve, for example, tasks having to be completed, plotting project milestones, allocating resources, and empirical data gathering. The primary concern is still how these elements come together, namely and reiterating, communicatively and interpretively across time.

When Schwarz (2005:25) refers to the facilitative consultant, along with other endeavours that could take a facilitative slant such as teaching or coaching, it is not clear exactly what type of consulting is in question. Yet, to highlight, one of the things that differentiates facilitative consulting from his list is that many types of consultants work with the whole of the organisation through its contracted stakeholders in a process that unfolds over time. This happens either actively as part of the design or it at least holds some implications for the organisation or community. The following professions or endeavours mostly exemplify such organisation-wide involvement: organisational development, organisational design, process consultation, change management or community development. 
What the above organisation-wide examples also have in common (and thereby differentiating it further from, say, the facilitative teacher) is the extent to which they are process minded. Ingrid Bens (2005:1), in our quoted definition of professional-vocational facilitation remarked that facilitation offers structure and process to interactions of groups. We abide with this professional-vocational characteristic in consideration of also the broader facilitative consulting endeavour, of being especially process minded.

To me this does not imply that it is the facilitator that would necessarily be the one that chooses, and at least not in isolation. Referring again to Ingrid Bens above, I would like to underscore the word she uses, namely to 'offer.' The facilitator would offer, whereas the consultant will perhaps inform. The facilitative consultant is at best (to borrow from Gerhard Egan's well known work, 2010), a skilled-helper. Shall we perhaps say skilled-'offerer'? In offering, when taken seriously, one finds an invitation to co-construction. To clarify what is already implicit. It is in 'offering' that it becomes clear that the choice for the word facilitation (above consultation) reflects an epistemological imperative.

\subsubsection{Anthem to consultation}

This does not entail that reference to practice of consulting was employed for lack of a better word. The idea of consulting is preferred as opposed to, say, facilitative project management. The preference for consulting, also, reflects an epistemological position and in its conjunction with the word facilitation is a critique against practitioner facilitation's belief in the possibility of neutrality whereby which, according to Hunter et al. (2007:26) and many others, the facilitator should refrain from taking part in the content of group discussions. These two words together, facilitation and consulting, surely presents a dialectic relationship that elsewhere I have referred to as presenting yet a third epistemological position and movement beyond objectivity or subjectivity. As Müller (2011a:3) puts it, this new epistemology (i.e., postfoundationalism) signifies a shift from the subjective to discourse, from the individual to social and situates the human subject in communicative praxis. Although Müller speaks about holistic pastoral ministry, what he says surely relates to the dialectic tension between facilitation and consultation. One of the things that comes to his mind is that said ministry involves a not-knowing approach while (and herein also lies the facilitators dialectic tension), at the same time taking an approach of active engagement.

\subsubsection{Consultant as exerting an experience-distant voice}

Furthering the choice for the word consulting: The choice has to do with what practical theologian, Henk de Roest (1998:35), calls (and in this he draws on cultural anthropology), the experience-distant voice. Hereby outsider rationality is presented as a reflection on the practices in question. What De Roest says is that religious academia needs to employ experience-distant perspectives such as, for example, social sciences. In our context the tables are turned in that the practical theological facilitator will present the experience-distant voice.

This experience-distant voice is in my estimation not just the task of social sciences, or in our scenario, theology, but also of art. If it also incorporates the arts then at the very least one should understand that the experience-distant voice is not an "I know better" voice. It rather represents a different transversal rationality than submitting an objective scientific rationale. Consequently it is the practical theologian's life, as a work of art (Müller 2011b:3-4), that becomes the experience-distant voice.

Following Van Huyssteen will explain why the facilitative consultant role is laden with transversal potential. Van Huyssteen (2000) puts forward an evolutionary biological argument concerning the origins of human rationality. If understood correctly, he says, this explains why 
our brains it seems are hardwired for cognitive fluidity (Van Huyssteen 2000:433). (Wo)man's propensity towards art, religion and culture came from our cognitive fluidity. I propose that these fluid rationalities provide experience-distant perspectives that could be put forward or embodied by the practical theologian facilitator.

Here over, other practitioner roles (e.g., project manager), is at greater risk of being engulfed by the prevalent scientific discourse of exact causal relationship and purely argumentative reasoning that is often void of context. In this respect Müller (2011b:2), conveys that arguments separated from a narrative dimension quite could possibly lead to becoming ahistorical and acontextual, and in the end irrelevant.

\subsubsection{Towards process consulting}

When referring to consulting I mostly have a specific understanding of consulting in mind. In the broad profession of consulting (change consultants, management consultants, image consultants, marketing consultants, and the like) the distinction is made between consultants (individuals or companies) whose expertise lie in a specific content area and those that focus rather on process, referred to as process consultants. Financial firms and engineering companies are typical examples of content-expert consultants, although one would rarely, if ever, refer to what they do as 'content' consulting. The differences between process and content consultants are no trivial matter. Mick Cope notes that this informs the whole style, approach and outcome of the consultancy process (2010:170).

This article aligns itself with the endeavour of process- rather than content consultants. Examples of process consultants would mostly include those that work with any matter relating to change in various fields: mergers and acquisitions, information technology implementation, company restructuring and required change from strategy development (Cameron \& Green 2009).

The idea of process is of course further accentuated in terms of a facilitative approach since even process consultants could work from a paradigm that conveys that they know best, even if it is still confined to all things process. Doctorate Practitioner, Alan Weiss, in his book Process Consulting mentions that successful consulting endeavours have mostly to do with putting in place conditions of success. Thus success is not in the first instance ascribed to expert content knowledge. Facilitators, Janoff and Weisbord (2005:244) resonates somewhat in that they set out to create conditions under which people will do their best using what they already have.

The notion of process consulting is linked to the field of organisational development, works with several social processes and is perhaps best ascribed to the ideas of Edgar Schein (Vail 2008:228). Vail (2008:219) in the chapter contribution, Process Wisdom, refers to process as the heart of the field of organisational development. It is important to remember that it is with Schein and other organisation development pioneers such as Chris Argyris and Donald Schon that the practice and origin of facilitation lie (Bens 2005:1).

\subsubsection{Communication}

The communication dimension of this role creates awareness around the presence and nature of voices, texts, and contexts (tangible or intangible, audible or inaudible, explicit or implicit). In addition the concern here is with creating platforms (which are not necessarily in-the-moment events, but still by means on which to interact, collaborate, and converse regarding the above. To aim outside the scope of this article for the moment: It is at communicative events or with collaborative platforms where one would consider wherein it is that one might find God's voice in a particular context. These contexts are varied and could include matters of family, ecology, politics, economy, and more. Voices of the marginalised, disenfranchised, those subdued to the 
misuse of positional (hierarchical awarded) power, or any concerns that advocating theology sensitized us towards has relevance in this dimension.

In reflecting on relevant voices the idea of hermeneutics aids us, especially in the context of a narrative-hermeneutic view.

Firstly though, suffice a general departure: I see hermeneutics, in line with Ganzevoort $(2009)^{11}$ as having a twofold understanding 1) "the classical focus on the relation between text and reader" and 2) the process of human interpretation that "places existential themes at the centre of investigation." 12

With this broader understanding of hermeneutics in mind, Heitink is still relevant. He notes that our historical context embeds us within the understanding formed by the tradition of the group, influenced by our personal capability for understanding and informing life history, wherein also psychological factors can help or hinder our religious (spiritual) understanding (Heitink 1993:190). Heitink's (1993:191) short formulation for the hermeneutical cycle relates to our facilitative consulting role and will help us reflect on what it is that influences participating voices, texts and contexts. In this cycle he refers to pre-understanding, observation or experience, interpretation and discourse, meaning-making "zingeving," practice / action "handelen."

Secondly, in my view one cannot dissociate hermeneutics also from narrative epistemology. This changes the view of hermeneutics, informed by a modernist paradigm, to that of being a postmodern, postfoundational pursuit. Consequently the task of hermeneutics is not to decipher in order to obtain the 'true' understanding, but hermeneutics becomes the quest, in that, it involves a communicative act of story construction in itself (i.e., a communicative praxis event), in order to obtain a collaborative interpreted understanding. Gerkin had already noted in 1991 that "...the central purpose of ministry practice is best fulfilled in assisting individuals, families, and communities in the transformation of life by means of the transformation and reinterpretation of their core stories" (Gerkin 1991:59). Afford me two adaptations to this: This is not only the purpose of ministry but also theology, and to be precise, practical theology and then also practical theological facilitation. Then, to be clear, this transformation and reinterpretation could take place in varied contexts, private, public and corporate. Even more specific in order to extend the notion of community that is mentioned, it includes institutions, organisations, cultures, societies and any other kind of shape or expression that people sharing life might take.

I have not touched on something that clearly relates to the facilitative consulting perspective, namely church development consultants. Even so I will only briefly comment on it here. The extent to which facilitative practices and values, process mindedness, communication and interpretation, and postmodern epistemology are employed differentiates facilitative consulting from church consultants. The latter could be practiced from a facilitative perspective and may well be, but is not necessarily, congruent with facilitative consulting. Doing so, being facilitative as a church consultant, does not automatically assume a facilitative approach in, and to practical theology. As Browning (1991:285) remarks that "[m]ost church development consultants do not go far [and I clarify: other than being descriptive as one of practical theology's tasks] in helping the congregation move through the next three movements of fundamental practical theology - the movements of historical, systematic, and strategic practical theology." Also, Browning (1991:285) refers to some consultants that see their task as primarily a social science endeavour and as objective and value-neutral. I see facilitative consulting as value-laden and perhaps drawing on the humanities in equal measure and more than on social sciences, while certainly not being restricted to a descriptive task.

11 Referring to his presidential address delivered at the International Academy of Practical Theology, titled Forks in the Road when Tracing the Sacred, see section heading Hermeneutics).

12 See Müller (2011a:3) for hermeneutics in relation to postfoundationalism. 


\section{CONCLUSION}

Much needs to be said still about how practical theology and facilitation, as understood in this article, could come together. While practical theology's tradition of inquiry, practice and particular personal accents certainly in my view deems my facilitative endeavour a practical theology informed one, I have not spoken about how the agenda of practical theology may come into view in facilitation. Surely this is a whole other matter as I do not think that what constitutes practical theology is defined by a narrow theological agenda but has more to do with the person of the practical theologian, a conclusion that Müller (2011b:4) also comes to.

At this stage of the journey my attempt has been to get the practical theologian, the practitioner facilitator and perhaps also the professional consultant to think creatively in the direction of what practical theological facilitation might entail. It asks for ongoing reflection in two ways: Firstly, reflection on facilitation as a value informed by a postmodern epistemological voice as it relates especially to groups in varied expressions (e.g., families, institutions, communities, organisations, and movements), and secondly, reflection on the ways and the concerns of practical theology in relation to the action area of facilitation.

\section{BIBLIOGRAPHY}

Arbnor, I \& Bjerke, B 2009. Methodology for creating business knowledge. 3rd ed. London: SAGE. Baart, A 2003. The fragile power of listening. Practical Theology in South-Africa 18(3), 136-156.

Bäumler, C 1976. Methoden der empirischen Sozialforschung in der Praktischen Theologie. Munchen: Matthias-Grunewald-Verlag.

Bens, I 2005. Facilitating with ease. Core Skills for Facilitators, Team Leaders and Members, Managers, Consultants, and Trainers. 2nd ed. San Francisco: Jossey-Bass.

Block, P 2000. Peter Block. Flawless Consulting. A guide to getting your expertise used. 2nd ed. San Francisco, CA: Pfeiffer.

Browning, D S 1991. A fundamental practical theology. Descriptive and strategic proposals, Minneapolis: Fortress Press.

Cameron, E \& Green, M 2009. Making sense of change management. A complete guide to the models, tools \& techniques of organizational change. 2nd ed. London: Kogan Page.

Capps, D 1999. The lessons of art theory for pastoral theology. Pastoral Psychology 47(5), 321-346.

Demasure, K \& Müller, J 2006. Perspectives in support of the narrative turn in pastoral care. NGTT 47(3\&4), 410-419.

Cummings, T G 2008. Handbook of Organization Development. Thousand Oaks, California: SAGE.

De Roest, H 1998. Communicative identity. Habermas' perspectives of discourse as a support for practical theology. Kampen: Uitgeverij Kok.

Dietterich, P M 1989. Systems model of the church in ministry and mission. Chicago: Center for parish development.

Dingemans, G D J 1996. Practical theology in the academy: A contemporary overview. The Journal of Religion 76(1), 82-96.

Ecotone, n.d., Ecotone, viewed 4 March 2012, from http://en.wikipedia.org/wiki/Ecotone

Fourie, D P 2010. Asking about ambivalence: A different kind of therapist neutrality. The American Journal of Family Therapy 38, 374-382.

Freedman, J \& Combs, G 1996. Narrative therapy: The social construction of preferred realities. New York: W.W. Norton and Company.

Ganzevoort, R R 2009. Forks in the road when tracing the sacred. Practical theology as hermeneutics of lived religion. Presidential address to the International Academy of Practical Theology, Chicago, 3 August 2009.Viewed 28 February 2012, from http://www.ruardganzevoort.nl/pdf/2009_Presidential. 
pdf

Gerkin, CV 1991. Prophetic pastoral practice. A Christian vision of life together. Nashville: Abingdon.

Heitink, G 1993. Praktishe theologie. Geschiedenis, theorie, handelingsvelden. Kampen: Uitgeverij Kok.

Hunter, D, Thorpe, S, Brown, H \& Bailey, A 2007. The art of facilitation. The essentials for leading great meetings and creating group synergy. Revised ed. San Francisco: Jossey-Bass.

Janoff, S \& Weisbord, M 2005. Facilitating the whole system in the room: A theory, philosophy, and practice for managing conflicting agendas, diverse needs, and polarized views, in Schuman, S (ed), The IAF handbook of group facilitation, 241-254. San Francisco: Jossey-Bass.

Kashtan, M 2005. The gift of self: The art of transparent facilitation, in Schuman, S. (ed), The IAF handbook of group facilitation, 573-590. San Francisco: Jossey-Bass.

Müller, J C 2011a. Postfoundational practical theology for a time of transition. HTS Teologiese Studies/ Theological Studies 67(1). Art.\#837, 5 pages. DOI: 10.4102/hts.v 67i1.837.

Müller, J C 2011b. (Outo) biografie as teologie. HTS Teologiese Studies/Theological Studies 67(3). Art. \#1113, 5 pages. http:// dx.doi.org/10.4102/hts. v67i3.1113

Müller, J C 2004. HIV/AIDS, narrative practical theology, and postfoundationalism: The emergence of a new story. HTS Teologiese Studies/Theological Studies 60(1\&2), 293-306.

Müller, J C 2000. Reis-geselskap. Die kuns van narratiewe pastorale gesprekvoering. Wellington: Luxverbi.

Müller, J C 1996. Om tot verhaal te kom: pastorale gesinsterapie. Pretoria: RGN Uitgewery.

Müller, J \& Schoeman, K 2004. Narrative research: A respectful and fragile intervention, Sociale Interventie (13)3, 7-13.

Müller, J, Van Deventer, W \& Human, L 2001. Fiction writing as metaphor for research: A narrative approach. Practical Theology in South Africa 26(2), 76-96.

Nichols, M P \& Schwartz, R C 1991. Family therapy. Concepts and methods. Boston: Allyn and Bacon.

Osmer, R R 2011. Practical theology: A current international perspective. HTS Teologiese Studies/ Theological Studies 67(2). \#Art. 1058, 7 pages. http:// dx.doi.org/10.4102/hts. v67i2.1058

Osmer, R R 2008. Practical theology: An introduction. Grand Rapids: Eerdmans.

Osmer, R R \& Schweitzer, F L (eds) 2003. Developing a public faith. New directions in practical theology. Essays in honor of James W. Fowler. St. Louis, Missouri: Chalice Press.

Palmer, S \& Whybrow, A (eds) 2008. Handbook of coaching psychology. A guide for practitioners. East Sussex: Routledge.

Paré, D A 1995. Of families and other cultures: The shifting paradigm of family therapy. Family Process 34(1), 1-19.

Poerksen, B 2004. The certainty of uncertainty: Dialogues introducing constructivism. Exeter, UK: Imprint Academic.

Schuman, S (ed) 2005. The IAF handbook of group facilitation, San Francisco: Jossey-Bass.

Schwarz, R 2005. The skilled facilitator, in Schuman S. (ed), The IAF handbook of group facilitation, 21-34. San Francisco: Jossey-Bass.

Tracy, D 1998. The analogical imagination: Christian theology and the culture of pluralism. New York: The Crossroad Publishing Company.

Troxel, J P 2005. Affirmative facilitation: An asset-based approach to process consultation, in Schuman, S (ed), The IAF handbook of group facilitation, 591-608. San Francisco: Jossey-Bass.

Vail, P B 2008. Process wisdom: The heart of organization development, in Cummings, T G (ed), Handbook of organization development, 219-236. Thousand Oaks, California: SAGE.

Van der Ven, J A 1993. Practical theology: An empirical approach. Kampen: Kok Pharos.

Van Huyssteen, J W 2000. Postfoundationalism and interdisciplinarity. A response to Jerome Stone. Zygon 35(2), 427-439.

Weis, A 2002. Process consulting. How to launch, implement, and conclude successful consulting projects, San Francisco: Jossey-Bass/ Pfeiffer.

White, S A (ed) 1999. The art of facilitating participation. Releasing the power of grassroots communication. New Delhi: SAGE.

White, S A \& Nair, K S 1999. The catalyst communicator: Facilitation without fear, in White S A (ed), The art of facilitating participation. Releasing the power of grassroots communication, 35-51. New Delhi: SAGE. 


\section{KEY WORDS}

Facilitation

Consulting

Practical Theology

Epistemology

Approaches

\section{TREFWOORDE}

Fasilitering

Konsultasie

Praktiese Teologie

Epistemologie

Benaderings

Author details

Dr. H Elmo Pienaar, Research Fellow,

Department of Practical Theology,

Faculty of Theology,

University of Pretoria.

Address:

Lynnwood Road,

Hatfield, 0083, Gauteng, South Africa.

Mobile phone: 082-4107645

Office phone: 012-4202669

Email address: elmo.pienaar@up.ac.za 